\title{
ANALISIS PENGENTASAN KEMISKINAN DALAM PRESPEKTIF PERAN GENDER DI PEDESAAN (Studi Kasus di Desa Kalangan Kec. Margomulyo Kab. Bojonegoro)
}

\author{
Oleh: \\ Andriyan Pujimulyatama \\ Bank Mandiri Madiun \\ Email: andriyanpm@gmail.com
}

\begin{abstract}
The objectives of this study were 1) to determine the characteristics of poor households in the village districts circles. Margomulyo Kab. Bojonegoro. 2) To determine the influence of age, education and gender roles to the family income. 3) To determine whether there is a significant difference in income after the role of gender in poor households. This study uses primary data obtained from questionnaires with 53 poor households. The analytical tool used is multiple regression with dummy variables and different test average. The results of 53 studies that poor households 23 respondents or $43 \%$ of elementary education (SD), 20 respondents or 38\% had not compleceted elementary school (SD) and 10 respondents or 19\% educated Junior High School (SMP). Types of jobs available 100 respondents $53 \%$ peasants'livelihood. Working hours in a day on average 7-9 hours. Wages earned Rp 20,000 to Rp 30,000 per day and for women workersor wives who work at $\mathrm{Rp} 20,000$ to $\mathrm{Rp} 25,000$ per day. Education elementary and junior high school education has no statistically significant effect on the family income of poor households, while age and gender roles have a statistically significant influence on the family income of poor households, if age is 1 (productive) it will add to the family income by Rp. 4683.643. Gender roles if the values is 1 (any gender roles) it will add to the family income by Rp. 24624.815. And there is a difference between family income existing gender roles and no gender roles.
\end{abstract}

Keywords: Poverty Alleviation, Gender Perspective, Wife Income

\begin{abstract}
Abstrak
Tujuan dari penelitian ini adalah 1) untuk mengetahui karakteristik rumah tangga miskin di kalangan kabupaten desa. Margomulyo Kab. Bojonegoro. 2) Untuk mengetahui pengaruh peran usia, pendidikan dan jenis kelamin terhadap pendapatan keluarga. 3) Untuk menentukan apakah ada perbedaan yang signifikan dalam pendapatan setelah peran gender dalam rumah tangga miskin. Penelitian ini menggunakan data primer yang diperoleh dari kuesioner dengan 53 rumah tangga miskin. Alat analisis yang digunakan adalah regresi berganda dengan variabel dummy dan uji beda rata-rata. Hasil 53 studi yang rumah tangga miskin 23 responden atau 43\% dari pendidikan dasar (SD), 20 responden atau 38\% tidak compleceted Sekolah Dasar (SD) dan 10 responden atau 19\% berpendidikan SMP (SMP). Jenis pekerjaan yang tersedia 100 responden 53\% peasants'livelihood. Jam kerja dalam sehari rata-rata 7-9 jam. Upah yang diperoleh Rp 20.000 hingga Rp 30.000 per hari dan untuk wanita workersor istri yang bekerja di $\mathrm{Rp} 20.000-\mathrm{Rp}$ 25.000 per hari. pendidikan pendidikan dasar dan SMP tidak berpengaruh
\end{abstract}


signifikan secara statistik pada pendapatan keluarga rumah tangga miskin, sementara peran usia dan jenis kelamin memiliki pengaruh yang signifikan secara statistik pada pendapatan keluarga rumah tangga miskin, jika usia 1 (produktif) akan menambah pendapatan keluarga sebesar Rp. 4.683,643. peran gender jika nilai adalah 1 (setiap peran gender) itu akan menambah pendapatan keluarga sebesar Rp. 24.624,815. Dan ada perbedaan antara peran gender pendapatan keluarga yang ada dan tidak ada peran gender.

Kata Kunci: Pengentasan Kemiskinan, perspektif gender, pendapatan Istri

\section{PENDAHULUAN}

Indonesia merupakan negara

yang kaya akan sumber daya alam dan berlandaskan hukum yang kuat.

Tujuan dari negara Indonesia sesuai dengan apa yang diamanatkan dalam Pembukaan Undang-Undang Dasar 1945 yaitu memajukan kesejahteraan umum dan mencerdaskan kehidupan bangsa. Tujuan tersebut akan tercapai apabila tingkat kemiskinan di Indonesia dapat dikurangi, agar tercapai maka perlu adanya upaya pengentasan kemiskinan. Populasi penduduk Indonesia pada tahun 2010 menurut BPS berjumlah 237.641.326 jiwa, dengan banyaknya jumlah penduduk Indonesia tidak dapat dipungkiri kemiskinan itu terjadi. Permasalahan yang terjadi di Indonesia sesuai fakta yang ada bahwa pertumbuhan ekonomi tidak tersebar secara merata di seluruh wilayah Indonesia, ini terbukti terjadi disparitas pendapatan antar daerah dan tingginya tingkat kemiskinan. 
Gambar 1. Perkembangan Kemiskinan di Indonesia tahun 2004-2012

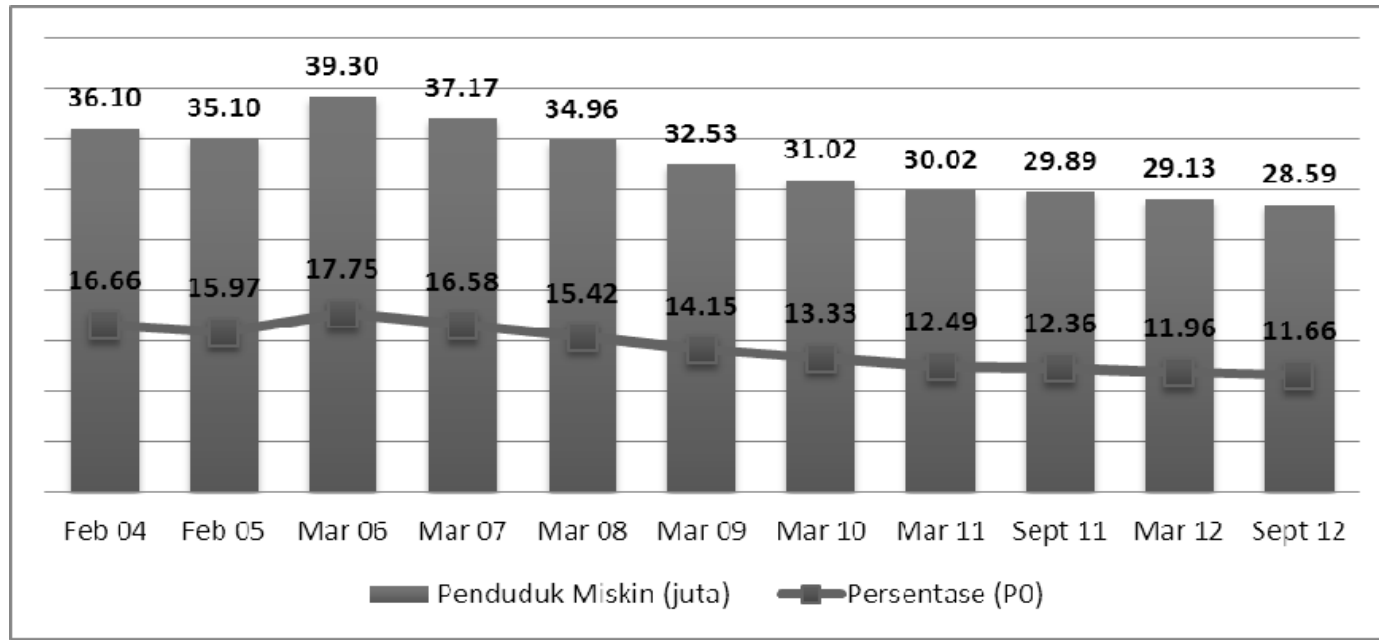

Sumber: Diolah dari data Survei Sosial Ekonomi Nasional (Susenas), 2012

Angka kemiskinan di

Indonesia berdasarkan Data Badan

Pusat Statistik (BPS, 2012) sebanyak 28.594.600 jiwa yang tersebar di seluruh pelosok Indonesia, di Jawa Timur sendiri angka kemiskinan tercatat 4.960 .500 jiwa atau $(13,08$ \%) data dari BPS September 2012. Di Jawa Timur jumlah penduduk miskin tercatat $1.606 .000(8,9 \%)$ jiwa di Kota dan $3.354 .600(16,88$ \%) jiwa di Desa. Ternyata persentasi penduduk miskin lebih banyak terdapat di Desa dibandingkan dengan Kota.

Jumlah penduduk miskin di Kab. Bojonegoro mencapai 227.089 jiwa, tingkat kemiskinan $18.8 \%$ dan garis kemiskinan di kab. Bojonegoro berkisar 211.213 rupiah. Ini menunjukan bahwa kab. Bojonegoro tingkat kemiskinannya masih relative tinggi. Indikator Kemiskinan Kabupaten Bojonegoro dapat dilihat pada gambar 2 .

Kemiskinan di dunia ini wanita yang menjadi korban paling menderita, wanita setiap hari harus menghadapi permasalahan yang begitu banyak dalam hidupnya, peran ganda wanita sebagai ibu rumah tangga berarti mereka harus mampu menjadi pendamping suami, mampu merawat dan mendidik anak. Adanya anggapan budaya yang menomorduakan peran wanita yang menjadikan mereka seringkali dipandang sebelah mata dalam masyarakat sosial. 


\section{Gambar 2. Indikator Kemiskinan Kabupaten Bojonegoro}

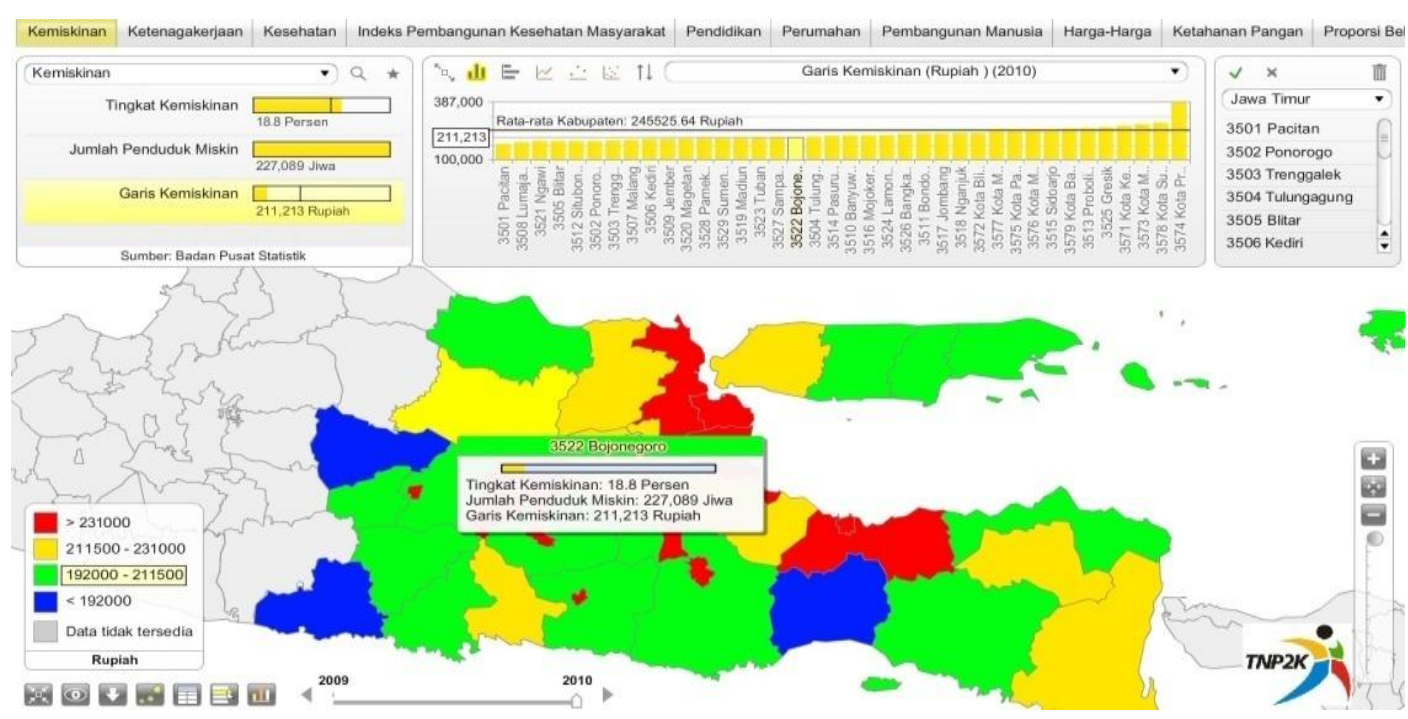

Sumber: www.tnp2k.go.id

Hal ini yang menjadikan terbatasnya akses-akses pendidikan ataupun ekonomi serta fasilitas sosial sulit bagi perempuan. Rendahnya tingkat pendidikan, pengetahuan dan pendapatan rumah tangga, kemungkinan besar menjadi sebab utama kemiskinan itu terjadi.

\section{Keterbatasan kemampuan} pendidikan dan pengetahuan yang dimiliki oleh kaum wanita di pedesaan menyebabkan perilaku serta kebiasaan setiap hari-harinya akan tetap sama seperti yang diajarkan dan diturunkan. Untuk itu demi kelangsungan diri dan keluarga, pihak wanita bekerja pada sector informal, sector pertanian atau buruh tani, perdagangan dan jasa dan buruh pabrik.

Kemiskinan pedesaan (rural proverty) dapat dikatakan sebagai salah satu topik pokok yang tidak mungkin dapat dilepaskan dari masalah pembangunan pedesaan, khususnya di negera-negara berkembang seperti di Indonesia ini karena sebagian besar dari penduduk tinggal di daerah pedesaan yang mana pada umumnya mereka hidup di bawah garis kemiskinan.

Peran wanita terutama di pedesaan sebagai sumber daya manusia cukup nyata partisipasinya khususnya dalam memenuhi fungsi keluarga dan rumah tangga bersama laki-laki, potensi yang dimiliki oleh 
wanita untuk menopang ekonomi keluarga memang cukup tinggi. Namun demikian wanita tidak menunjukan diri atau mengklaim bahwa mereka menjadi penyangga utama ekonomi keluarga. Hal inilah yang menjadi alasan penulis untuk melakukan penelitian di desa Kalangan dengan judul "Analisis Pengentasan Kemiskinan Dalam Prespektif Peran Gender di Pedesaan. Hidayat (2006) Teknik analisis menggunakan table tunggal, table silang,dan analisis kualitatif. Hasil penelitian yaitu pendapatan yang diperoleh di TPA Jatibarang sebagian besar lebih tinggi dibandingkan dengan upah minimum regional (UMR) Propinsi Jawa Tengah

\section{METODE PENELITIAN}

Penelitian dilakukan pada Desa Kalangan Kecamatan Margomulyo Kabupaten Bojonegoro. Secara umum penelitian ini didasarkan atas pertimbangan, kesesuaian, dengan substansi penelitian. Alasan memilih lokasi penelitian di Desa Kalangan karena Desa Kalangan Kecamatan Margomulyo Kabupaten Bojonegoro merupakan salah satu Desa yang masih terdapat masyarakat yang diketegorikan sebagai masyarakat miskin dan berpotensi memiliki jumlah rumah tangga miskin terbesar diantara desa-desa lain di Kecamatan Margomulyo.

Jenis penelitian yang digunakan adalah analisis deskriptif kuantitatif. Populasi dalam penelitian ini adalah rumah tangga yang dikategorikan sebagai rumah tangga miskin yang tinggal di Desa Kalangan Kecamatan Margomulyo Kabupaten Bojonegoro berjumlah 263 Kepala Keluarga. Sampel dalam penelitian adalah rumah tangga miskin dan rumah tangga miskin yang ada peran gender saja. Jumlah sampel sebesar $20 \%$ dari populasi, yaitu diperoleh $20 \%$ x $263=52,6$ atau bila dibulatkan menjadi 53 sampel.

Data yang digunakan dalam penelitian ini adalah cross-section. Metode analisis data yang digunakan dalam penelitian ini ada 2 cara yaitu: Regresi linear berganda yang diterapkan untuk data cross-section dan Uji Beda Pendapatan Rata-rata.

Bentuk rumusan matematik dari analisis linier berganda yang 


$\begin{array}{lccl}\text { digunakan } & \text { adalah } & \text { dengan } & \mathrm{D}=1 \text { jika ada wanita yang } \\ \text { menggunakan } & \text { metode } & \text { regresi } & \text { bekerja }\end{array}$

berganda dengan variabel Dummy untuk mengetahui pengaruh variabel dependen yaitu Pendapatan rumah tangga, terhadap variabel independen yaitu Pendidikan, Usia dan Peran Gender, adalah sebagai berikut :

$Y=\beta_{0}+\beta_{1} D_{1}+\beta_{2} D_{2}+\beta_{3} D_{3}+\alpha$

Dimana:

$\mathrm{Y}=$ Pendapatan Rumah Tangga

$\alpha \quad=$ konstanta

$\beta_{1} \quad=$ koefisien regresi dari (D1)

$\beta_{2} \quad=$ koefisien regresi dari (D2)

$\beta_{3}=$ koefisien regresi dari (D3)

$\mathrm{D}_{1} \quad=$ Model Pendidikan Kepala

Rumah Tangga sebagai variabel

Dummy (skors)

$\mathrm{D}=0$ jika tidak tamat SD

$\mathrm{D} \quad=1$ jika tamat SD

$\mathrm{D}=2$ jika tamat SMP

D $=3$ jika tamat SMA

$\mathrm{D}_{2} \quad=$ Model Usia Kepala Rumah

Tangga sebagai variabel Dummy (skors)

D $\quad=0$ jika tidak Usia Produktif

$\mathrm{D} \quad=1$ jika Usia Produktif

$\mathrm{D}_{3}=$ Model Peran Gender sebagai variabel Dummy (skors)

$\mathrm{D}=0$ jika tidak ada wanita yang bekerja

\section{PEMBAHASAN}

\section{Karakteristik Rumah Tangga Miskin}

\section{Pendidikan}

Hasil wawancara dengan 53 responden disimpulkan bahwa ratarata pendidikan hanya sampai tingkat Sekolah Dasar (SD) dan tidak semuanya menyelesaikan pendidkan Sekolah Dasar (SD), hasilnya dari 53 responden rumah tangga miskin 23 responden atau $43 \%$ berpendidikan Sekolah Dasar (SD), 20 responden atau $38 \%$ tidak tamat Sekolah Dasar (SD) dan 10 responden atau $19 \%$ berpendidikan Sekolah Menengah Peratama (SMP). Kenapa hal tersebut terjadi, alasan dari responden yaitu persoalan ekonomi dan persepsi masyarakt bahwa mampu baca tulis dan berhitungpun sudah dirasa cukup.

Mata pencaharian dari masyarakat Desa Kalangan rata-rata masyarakat miskin yang tinggal disana mempunyai latar belakang pekerjaan yang sama yang mana mata pencahariaannya sebagai buruh tani, dari 53 responden yang ada 
secara keseluruhan atau $100 \%$ mata pencaharian Buruh Tani. Sedangkan untuk lama jam kerja dalam satu hari rata-rata $7-9$ jam, yang dimulai jam 05:30 WIB sampai jam 09:00 WIB dan mulai bekerja lagi jam 02:30 WIB sampai Jam 17:00 WIB.

Jumlah Tanggungan Keluarga

Tabel 1. Jumlah Tanggungan Keluarga

\begin{tabular}{ccc}
\hline Jumlah & & \\
\hline $\begin{array}{c}\text { Tanggungan } \\
\text { Keluarga }\end{array}$ & Frekuensi & $\%$ \\
\hline & & \\
\hline 1 & 3 & 6 \\
\hline 2 & 7 & 13 \\
\hline 3 & 16 & 30 \\
\hline 4 & 19 & 36 \\
\hline 5 & 8 & 15 \\
\hline Jumlah & 53 & 100 \\
\hline
\end{tabular}

Sumber : Data primer diolah, 2014

Berdasarkan tabel diatas dapat dilihat bahwa jumlah tanggungan keluarga yang paling banyak pada rumah tangga miskin berada pada kelompok sama dengan 4 orang per rumah tangga yaitu sebanyak 19 responden atau 36\%, artinya setiap kepala keluarga harus menanggung 4 anggota keluarga. Semakin besar anggota keluarga semakin banyak pengeluaran untuk kebutuhan pokok. Kemudian jumlah tanggungan keluarga yang paling sedikit berada pada kelompok sama dengan 1 orang per rumah tangga yaitu sebanyak 3 responden atau $6 \%$.

\section{Kondisi Ekonomi}

53 responden yang ada ratarata semua mata pecahariannya sebagai buruh tani baik kepala keluarga dan istrinya yang bekerja, dari 53 responden terdapat 26 responden yang istrinya bekerja sebagai buruh tani. Untuk pendapatan dari hasil bekerja sebagai buruh tani yaitu sebesar Rp 20.000 sampai Rp. 30.000 perhari dan untuk tenaga kerja wanita atau istri yang bekerja sebesar Rp 20.000 sampai Rp 25.000 per hari. Hal itu tidak serta merta diperoleh setiap hari secara rutin, dari sini dapat diketahui untuk memenuhi kebutuhan setiap hari rumah tangga miskin masih belum layak, ditambah lagi untuk kebutuhan sekolah anak-anaknya.

Dari 53 responden Rumah Tangga Miskin dapat diketahui pendapatan per hari dengan membaca tabel di bawah. 


\begin{tabular}{|lcc}
\hline Tabel 2. & $\begin{array}{c}\text { Pendapatan per } \\
\text { Rumah Tangga Miskin } \\
\text { di Desa Kalangan }\end{array}$ \\
\hline $\begin{array}{c}\text { Interval Pendapatan } \\
\text { Rumah Tangga }\end{array}$ & $\begin{array}{c}\text { Kepala } \\
\text { rumah } \\
\text { tangga }\end{array}$ & $\begin{array}{c}\text { Ibu } \\
\text { Rumah } \\
\text { tangga }\end{array}$ \\
\hline < Rp. 19.500 & 0 & 0 \\
\hline Rp. $20.000-$ Rp. 24.500 & 1 & 3 \\
\hline Rp. $25.000-$ Rp. 29.500 & 8 & 23 \\
\hline > Rp. 30.000 & 43 & 0 \\
\hline
\end{tabular}

Sumber: Data Primer diolah, 2014

\section{Status Rumah}

Status kepemilikan Rumah merupakan indikator dari kemapanan ekonomi suatu rumah tangga, dari status dapat kita ketahui kemampuan ekonomi suatu rumah tangga. Untuk lebih jelasnya dapat dilihat gambar dibawah:

Dari tabel diatas dapat disimpulkan bahwa dari 53 responden terdapat $75 \%$ atau 40 kepala keluarga yang status rumahnya masih milik orang tua belum mempunyai rumah sendiri, dan $25 \%$ atau 13 kepala keluarga status rumah tinggal milik sendiri dan status sewa tidak ada. Dari hasil tabel yang ada bahwa kepemilikan rumah mencerminkan kemampuan ekonomi suatu rumah tangga.

\section{Pembahasan}

\section{Uji F}

Pengujian hasil regresi dengan uji $\mathrm{F}$ bertujuan untuk mengetahui tingkat signifikansi atas pengaruh antara variabel bebas secara keseluruhan yaitu pendidikan SD (B1), pendidkan SMP (B2), Usia (B3) dan Peran Gender (B4) terhadap Pendapatan Rumah Tangga Miskin (Y).

Dari hasil regresi diatas diperoleh F-statistik sebesar (487.016), sedangkan pada signifikansi $5 \%$ dengan df1 = k-1 = 4 dan $\mathrm{df} 2=\mathrm{n}-\mathrm{k}=48$ diperoleh $\mathrm{F}$ tabel sebesar (2.79). Hal ini dapat disimpulkan bahwa F-Statistik (487.016) > F-Tabel (2.79), berarti menolak H0 dan menerima Hi. Artinya bahwa Pendidikan SD (B1), Pendidikan SMP (B2), Usia (B3) dan Peran Gender (B4) secara bersama sama mempengaruhi pendapatan rumah tangga rumah tangga miskin (Y).

\section{Uji t}

\section{Pendidikan}

Berdasarkan hasil regresi diperoleh hasil $t_{\text {-hitung }}=1,620$ sehingga diperoleh hasil t-hitung 
$(1,620)<t_{\text {-tabel }}(2,010)$, maka keputusan adalah hipotesis nol (H0) diterima dan (Ha) ditolak. Hasil dari uji t menunjukkan bahwa variabel Pendidikan $\left(D_{1}\right)$ secara parsial tidak berpengaruh terhadap Pendapatan rumah tangga.

\section{Usia}

Berdasarkan hasil regresi diperoleh hasil $\mathrm{t}_{\text {-hitung }}=3,883$ sehingga diperoleh hasil t-hitung $(3,883)>t^{-t a b e l} \quad(2,010)$, maka keputusan adalah hipotesis nol (H0) ditolak dan menerima hipotesis alternative (Ha). Hasil dari uji $\mathrm{t}$ menunjukkan bahwa variabel Usia $\left(\mathrm{B}_{2}\right)$ secara parsial berpengaruh positif dan berpengaruh signifikan terhadap Pendapatan rumah tangga.

\section{Peran Gender}

Berdasarkan hasil regresi diperoleh hasil $\mathrm{t}_{\text {-hitung }}=36,436$ sehingga diperoleh hasil $t$-hitung $(36,436)>t_{-t a b e l}(2,010)$, maka keputusan adalah hipotesis nol (H0) ditolak dan menerima hipotesis alternative (Ha). Hasil dari uji $\mathrm{t}$ menunjukkan bahwa variabel Peran Gender $\quad\left(B_{3}\right)$ secara parsial berpengaruh positif dan berpengaruh signifikan terhadap Pendapatan rumah tangga.

\section{Hasil Analisis Regresi Linier} Berganda dengan Varibel Dummy

Dari hasil estimasi regresi linier berganda diperoleh persamaan regresi sebagai berikut:

$$
\begin{gathered}
\mathrm{Y}=23920.784+766.849 \mathrm{D}_{1}+ \\
4663.832 \mathrm{D}_{2}+24629.230 \mathrm{D}_{3} \\
R^{2}=0,968 F_{\text {hitung }}=487,016
\end{gathered}
$$

Interpretasi dari persamaan diatas adalah:

a) Nilai Konstanta sebesar 23920,784 menunjukan apabila pendidikan, usia dan peran gender sebagai variabel independent konstan maka besarnya pendapatan rumah tangga per hari sebesar 23920,784 rupiah.

b) Untuk variabel boneka (dummy variable - $\mathrm{D}_{1}$ ) yaitu Tingkat Pendidikan, artinya jika Pendidikan bernilai 1 (tamat SD) nilai 2 (tamat SMP) nilai 3 (tamat SMA), maka akan menambah pendapatan rumah tangga sebesar 766,849 rupiah dan jika tidak tamat bernilai "nol". Hasil estimasi menunjukan tidak signifikan nilai parameter regresinya, berarti variabel 
pendidikan tidak berpengaruh nyata terhadap besarnya tingkat pendapatan rumah tangga.

c) Untuk variabel boneka (dummy variable $-\mathrm{D}_{3}$ ) Usia, artinya jika Usia bernilai 1 (Produktif) maka akan menambah pendapatan rumah tangga sebesar 4663,832 rupiah, sedangkan untuk Usia bernilai "nol" (Tidak Produktif) tidak berpengaruh terhadap pendapatan rumah tangga. Hasil estimasi menunjukan signifikan nilai parameter regresinya berarti variabel Usia berpengaruh nyata terhadap besarnya tingkat pendapatan rumah tangga.

d) Untuk variabel boneka (dummy variable - $\left.\mathrm{D}_{4}\right)$ Peran Gender, artinya jika Peran Gender bernilai 1 (Ada Peran Gender) maka akan menambah pendapatan rumah tangga sebesar 24629,230 rupiah sedangkan untuk Peran Gender bernilai "nol" (Tidak Ada Peran Gender) tidak berpengaruh terhadap pendapatan rumah tangga. Hasil estimasi menunjukan signifikan nilai parameter regresinya berarti variabel Usia berpengaruh nyata terhadap besarnya tingkat pendapatan rumah tangga.

\section{Uji Determinasi $\left(\boldsymbol{R}^{2}\right)$}

Diketahui bahwa koefisien determinasi sebesar (0.968) atau (96\%), berarti bahwa keberadaan variabel Pendidikan(B1), pendidkan SMP (B2), Usia (B3) dan Peran Gender (B4) sebesar 96\% atau dengan kata lain Pendidikan, Usia dan Peran Gender mampu memberikan kontribusi dalam menjelaskan pendapatan rumah tangga sebesar 96\%, sedangkan sisanya $4 \%$ dijelaskan variabel lain diluar variabel tersebut.

\section{Uji Beda Rata-Rata}

Hasil dari Uji beda Rata-rata menunjukkan sebesar 31.929.

Berdasarkan hasil regresi diperoleh hasil $\mathrm{t}$-hitung $=31,929$ sehingga diperoleh hasil $t$-hitung $(31,929)>t_{\text {-tabel }}(2,06)$, maka keputusan adalah hipotesis nol (H0) ditolak dan menerima hipotesis alternative (Ha). Artinya bahwa terdapat perbedaan pendapatan antara keluarga yang ada peran gender dengan tidak ada peran gender. 


\section{KESIMPULAN}

Berdasarkan hasil analisis data dan pembahasan hasil penelitian yang telah dilakukan, maka dapat diperoleh kesimpulan sebagai berikut:

Karakterisitik sosial ekonomi rumah tangga miskin di Desa Kalangan Kecamatan Margomulyo Kabupaten Bojonegoro rata-rata pendidikan hanya sampai tingkat Sekolah Dasar (SD) dan tidak semuanya menyelesaikan pendidikan Sekolah Dasar (SD), hasilnya dari 53 responden rumah tangga miskin 23 responden atau $43 \%$ berpendidikan Sekolah Dasar (SD), 20 responden atau $38 \%$ tidak tamat Sekolah Dasar (SD) dan 10 responden atau $19 \%$ berpendidikan Sekolah Menengah Peratama (SMP). Selain pendidikan juga jenis pekerjaan yaitu dari 53 responden yang ada secara keseluruhan atau $100 \%$ mata pencaharian Buruh Tani. Sedangkan untuk lama jam kerja dalam satu hari rata-rata 7 - 9 jam, yang dimulai jam 05:30 WIB sampai jam 09:00 WIB dan mulai bekerja lagi jam 02:30 WIB sampai Jam 17:00 WIB. Upah yang didapat dari bekerja sebagai buruh tani yaitu sebesar Rp 20.000 sampai Rp. 30.000 perhari dan untuk tenaga kerja wanita atau istri yang bekerja sebesar Rp 20.000 sampai Rp 25.000 per hari. Hal itu tidak serta merta diperoleh setiap hari secara rutin, dari sini dapat diketahui untuk memenuhi kebutuhan setiap hari rumah tangga miskin masih belum layak, ditambah lagi untuk kebutuhan sekolah anak-anaknya. Jumlah tanggungan keluarga juga masih tinggi yaitu paling banyak 19 responden atau $36 \%$ mempunyai jumlah tanggungan keluarga 4 orang per rumah tangga.

Bahwa Pendidikan secara statistik tidak memiliki pengaruh signifikan terhadap pendapatan rumah tangga rumah tangga miskin sedangkan usia dan peran gender secara statistik memiliki pengaruh signifikan terhadap pendapatan rumah tangga rumah tangga miskin.

Terdapat perbedaan pendapatan antara keluarga yang ada peran gender dengan tidak ada peran gender. 


\section{DAFTAR PUSTAKA}

Arikunto, Suharsimi, 2010. Prosedur Penelitian; Edisi Revisi, PT. Asdi mahasatya, Jakarta.

Badan Pusat Statistik (BPS), 2000. Studi Penentuan Kriteria Penduduk Miskin : Metodologi Penentuan Rumah Tangga Miskin 2000, Jakarta: Badan Pusat Statistik.

BPS, 2012. Berita Resmi Statistik. Penerbit Badan Pusat Statistik Provinsi Jawa Timur.

BPS, 2013. Berita Resmi Statistik. Penerbit Badan Pusat Statistik Provinsi Jawa Timur.

Boediono., 1992. Ekonomi Makro. Seri Sinopsis Pengantar Ilmu Ekonomi No.2. Edisi 4.BPFE, Yogyakarta.

Fakih, Mansour., 1996. Analisis Gender \& Trasformasi Sosial; Pustaka Pelajar, Yogyakarta.

Fergus, Dwianti J., Diah Widyawati, 1995. Dampak Jumlah dan Umur Anak Terhadap Kecenderungan Bekerja Perempuan Menikah, dalam Pasar Kerja dan Produktifitas di Indonesia. Kantor Menteri Negara

Kependudukan/BKKBN. Jakarta.

Handayani Trisakti., Sugiarti. 2008. Konsep dan Teknik Penelitian Gender; Edisi Revisi, UMM
Press, Malang.

Haryanto, W., 2008. Jurnal Ekonomi Pembangunan: Peran Aktif Wanita dalam Peningkatan Pendapata Rumah Tangga Miskin, 9(2):216-227

Herawati, 1998. Ensiklopedi Populer Politik Pembangunan

Pancasila, Bumi Aksara, Jakarta.

Hidayat, W., 2006. Jurnal Penelitian Fakultas Ekonomi Universitas Semarang: Analisis peran Ganda Pemulung Wanita Pada Tempat Pembuangan Akhir (TPA) Jatiberang Kodia Semarang, 5 (1):35-41.

Kuncoro, Mudrajad., 2011. Metode Kuantitatif, edisi ke-4, UPPSTIM YKPN, Yogyakarta.

Lilja. N., Randolph, T.F., 1998. Estimating Gender Differences in Agricultural Productivity: Biases due to Omission of Gender Influenced Variable and Endogenity of Regressors. Selected Paper Submitted to American Agricultural Economics Association Annul Meeting, 1998, Utah.

Mubyarto., 2003. Membangun Sistem Ekonomi; BPFE, Yogyakarta.

Prayitno Hadi., Arsyad Lincolin., 1987. Petani Desa dan Kemiskinan; Edisi Pertama, BPFE, Yogyakarta. 
Puspita, H. 2012. Gender dan Keluarga: Konsep dan Realita di Indonesia. PT IPB PRESS. Bogor.

Sajogyo, Pudjiwati., 1983. Peranan Wanita dalam Perkembangan Masyarakat Desa. Jakarta: CV. Rajawali.

Sugiyono., 2006. Metode Penelitian Bisnis, CV. Alfabet, Bandung.

Sugiyono., 2009. Metode Penelitian Administrasi Dilengkapi dengan Metode R\&D, Edisi Revisi, CV. Alfabet, Bandung.

Suryawati, Criswardani., 2005. Jurnal Manajemen Pelayanan Kesehatan Universitas Diponegoro: Memahami Kemiskinan Secara Multidemensional, 8 (03)
Todaro, Michael P., 2000, Pembangunan Ekonomi di Dunia Ketiga Edisi Ketujuh terjemahan, Penerbit Erlangga, Jakarta.

Todaro, Michael P., 2006, Pembangunan Ekonomi jilid satu, Edisi Kesembilan terjemahan, Penerbit Erlangga, Jakarta.

Wijayanti, D.M., 2010. Jurnal Komunitas Universitas Negeri Semarang: Belenggu

Kemiskinan Buruh Perempuan Pabrik Rokok, 2 (2):84-93.

Winardi. 1992. Manajemen Perilaku Organisasi. PT. Citra Aditya Bakti, Bandung.

Akses situs www.tnp2k.go.id 